\title{
Recommended Best Practices for Process Monitoring Instrumentation in Pharmaceutical Freeze Drying-2017
}

\author{
Steven Nail, ${ }^{1,11}$ Serguei Tchessalov, ${ }^{2}$ Evgenyi Shalaev, ${ }^{3}$ Arnab Ganguly, ${ }^{4}$ Ernesto Renzi, ${ }^{4}$ Frank Dimarco, ${ }^{4}$ \\ Lindsay Wegiel, ${ }^{1}$ Steven Ferris, ${ }^{1}$ William Kessler, ${ }^{5}$ Michael Pikal, ${ }^{6}$ Greg Sacha, ${ }^{1}$ Alina Alexeenko, ${ }^{7}$ \\ T. N. Thompson, ${ }^{8}$ Cindy Reiter, ${ }^{8}$ James Searles, ${ }^{9}$ and Paul Coiteux ${ }^{10}$
}

Received 7 December 2016; accepted 31 January 2017; published online 15 February 2017

\begin{abstract}
Recommended best practices in monitoring of product status during pharmaceutical freeze drying are presented, focusing on methods that apply to both laboratory and production scale. With respect to product temperature measurement, sources of uncertainty associated with any type of measurement probe are discussed, as well as important differences between the two most common types of temperature-measuring instruments - thermocouples and resistance temperature detectors (RTD). Two types of pressure transducers are discussed-thermal conductivity-type gauges and capacitance manometers, with the Pirani gauge being the thermal conductivity-type gauge of choice. It is recommended that both types of pressure gauge be used on both the product chamber and the condenser for freeze dryers with an external condenser, and the reasoning for this recommendation is discussed. Developing technology for process monitoring worthy of further investigation is also briefly reviewed, including wireless product temperature monitoring, tunable diode laser absorption spectroscopy at manufacturing scale, heat flux measurement, and mass spectrometry as process monitoring tools.
\end{abstract}

KEY WORDS: heat flux measurement; mass spectrometry; pressure measurement; process analytical technology; temperature measurement; tunable diode laser absorption spectroscopy.

\section{INTRODUCTION}

Pharmaceutical scientists and engineers recognize the importance of respecting the intellectual property of other organizations, particularly proprietary information regarding specific drug products and associated processes. However, there are other subject areas where we all stand to benefit from sharing information. In pharmaceutical freeze drying, an example of this is the sharing of information concerning developmental and operational aspects of freeze drying; for

\footnotetext{
${ }^{1}$ Baxter Medical Products R\&D, LLC 927 S. Curry Pike, Bloomington, Indiana 47403, USA.

${ }^{2}$ Pfizer Global Research, Andover, Massachusetts, USA.

${ }^{3}$ Allergan, Inc., Palo Alto, California, USA.

${ }^{4}$ IMA Life, Inc., Tonawanda, New York, USA.

${ }^{5}$ Physical Sciences, Inc., Andover, Massachusetts, USA.

${ }^{6}$ University of Connecticut, Storrs, Connecticut, USA.

${ }^{7}$ Department of Aeronautical Engineering, Purdue University, West Lafayette, Indiana, USA.

${ }^{8}$ Millrock Technology, Kingston, New York, USA.

${ }^{9}$ Injectable Drug Product Technology Services, Pfizer, Inc., McPherson, Kansas, USA.

${ }^{10}$ SP Scientific, Gardiner, New York, USA.

${ }^{11}$ To whom correspondence should be addressed. (e-mail: steven_nail@baxter.com)
}

example, the scientific justification for acceptance criteria for leak rate testing of freeze dryers (1), acceptance criteria for cake appearance, sampling plans for residual moisture testing, process monitoring instrumentation, equipment qualification, cleaning validation, process validation, and so forth. Why is such an effort useful? First, uncertainty over best practices in these areas of freeze drying operations can lead to delays resulting from lengthy internal debate over what really constitutes "best practice," and it seems common that unnecessarily conservative positions are taken, particularly when deep expertise in the subject may be lacking. Second, there is often not enough reflective thought about the scientific and engineering reasons behind such practices. "Because we've always done it that way" is an all-toocommon response. It is hoped that the sharing of information between companies will promote a deeper understanding of the science and engineering of pharmaceutical freeze drying, which is a fundamental component of the Quality by Design paradigm. Finally, on a more practical level, none of us want to be taken by surprise during discussions with any regulatory agency, and have no thoughtful response to offer when asked about the reasoning behind our practices.

We hope that the output of this collaborative effort is a series of articles on best practices in pharmaceutical freeze drying that represent a consensus of opinion among thought 
leaders in both academics and industry. The broad objectives are to bring out points to consider, to foster debate over best practices, and to stimulate reflective thought. Also, thinking through best practices can raise questions that require some research to answer. Another objective of this effort is to highlight some of these questions in the hope of attracting interest in pursuing answers.

We also need to recognize that there are many questions for which thoughtful people may disagree on the answer. There is no intent in this series to "lay down the law" as to what must be done. Everyone involved in freeze drying, however, should be able to articulate the reasoning behind their current practice.

These articles assume a basic grasp of the fundamentals of freeze drying by the reader, such as fundamental aspects of the sublimation of ice, heat and mass transfer in freeze drying, and the basics of process control. Neither this article nor those to follow are intended to be tutorial.

This communication deals with recommended best practices for freeze dryer instrumentation, particularly that used for monitoring the status of the product during freeze drying and perhaps for equipment capability testing. Temperature and pressure are both critical variables affecting heat transfer, mass transfer, process efficiency, and product quality. For this reason, particular emphasis is placed on product temperature and pressure measurement within the freeze dryer. The methods discussed here are limited to techniques that are equally applicable at both laboratory and production scale. "Single-vial" techniques, for example, are out of scope of this discussion.

Finally, we recognize that "best practice" changes over time as new technology matures and as process understanding deepens. The title of the article includes " 2017 " to capture the idea that this is a "snapshot" of what we consider to be current best practice. We include a brief survey of developing technology that may become worthy of "best practice" recognition in the next few years.

\section{Product Temperature Measurement}

When developing a freeze dry cycle for any product, it is essential to collect reliable data on product temperature throughout the freeze dry process. It must be ascertained that the product is frozen to a suitably low temperature and held at that temperature for a sufficient time. Identifying appropriate conditions for primary drying, which is usually the longest part of a freeze dry cycle, requires that the upper product temperature limit for primary drying be established based on materials characterization, and that the product temperature during primary drying remain a safe margin below this upper limit without being unnecessarily low, resulting in an unnecessarily prolonged freeze dry cycle. Recommended best practice for measuring product temperature in individual vials is illustrated in Fig. 1. Several features should be evident. First, the thermocouple wire is thin (30 gauge, in this case). The fine wire facilitates handling the lead wire in such a way that it does not disrupt vials in its path, and helps in locating the junction at a precise location. Note also that there is a device in the neck of the vial (designed and built by Alan MacKenzie, Mercer Island, WA) incorporating a guide tube through which the thermocouple wire is threaded. This enables locating the thermocouple tip in the center of the vial and touching the bottom. Our view is that locating the thermocouple in the center of the vial and touching the bottom is best practice, despite the widely held opinion that the thermocouple tip should be placed "just off" the bottom. Advocates of the "just off the bottom" point of view often state that, if the tip of the thermocouple touches the bottom, then it is measuring the temperature of the glass, not the temperature of the product. This seems to assume that there is a temperature discontinuity between the glass and the product in contact with the glass. In fact, there is no such discontinuity. "Just off the bottom" is subjective because this is not the same distance to all people. Keep in mind that there is a temperature gradient across the frozen material during primary drying, with the warmest point at the bottom of the vial, where risk to the product is highest. Also, given the time course of the shape of the sublimation front during primary drying, where it becomes more convex (when looking downward) as primary drying proceeds, the response of a thermocouple is highly dependent upon its position in the vial, both vertically and radially. The last ice to disappear is usually at the bottom center of the vial (2). The device used to secure the placement of the thermocouple should have openings comparable in area to the open area of the lyostoppers when in the partially seated position, thus offering approximately the same resistance to mass transfer as a partially inserted stopper.

While there is no question of the importance of product temperature monitoring during laboratory-scale cycle development, practices across the industry differ widely over the use of product temperature beyond the laboratory scale.

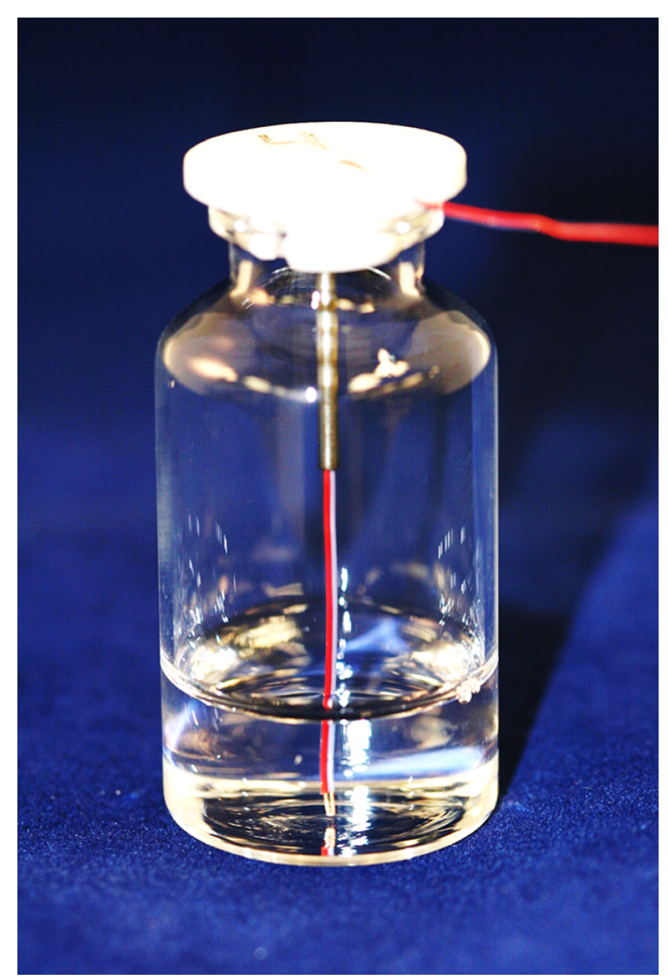

Fig. 1. Best practice for measuring product temperature in individual vials includes using fine-gauge thermocouple wire along with a device for maintaining the location of the tip of the thermocouple in the center of the vial, touching the bottom 
There is widespread recognition of the usefulness of monitoring product temperature during scale-up, to assure that the time course of product temperature at larger scale is reasonably consistent with laboratory-scale data. The same consideration applies to cycle validation, stability batches at larger scale, transfer of cycles between manufacturing sites, manufacture of clinical supplies, and so forth.

Before going further, it is important to discuss some of the problems and sources of uncertainty associated with product temperature measurement. First, the presence of any temperature probe introduces a bias in monitored vials relative to non-monitored vials. The temperature-measuring device, regardless of whether it is a thermocouple, a resistance temperature detector (RTD), or any other type of device, can act as a nucleation site for ice. This is illustrated in Fig. 2, where nucleation temperatures for vials with a temperature probe in the vial are compared with nucleation temperatures with the temperature probe fastened to the outside surface of the vial, where it cannot influence nucleation. The average nucleation temperature with a probe in the vial is about $5^{\circ} \mathrm{C}$ higher than the nucleation temperature with the probe on the outer surface of the vial (the uncertainty in temperature associated with the measuring element being on the outside surface of the vial is no more than $0.5^{\circ} \mathrm{C}$ ). Since monitored vials tend to supercool less than the rest of the batch, they freeze more slowly. Slower freezing results in a larger average ice crystal size. As the ice sublimes, larger crystals leave larger channels in the partially dried material. These larger channels have lower resistance to flow of water vapor. As a result, monitored vials tend to sublime more rapidly than the rest of the batch. Ten percent faster is a reasonable estimate (unpublished data). This bias must be taken into account in establishing the end of primary drying in cases where product temperature is the only cycle end point indicator. This issue is most important for stochastic ice nucleation; that is, nucleation of ice proceeds randomly when

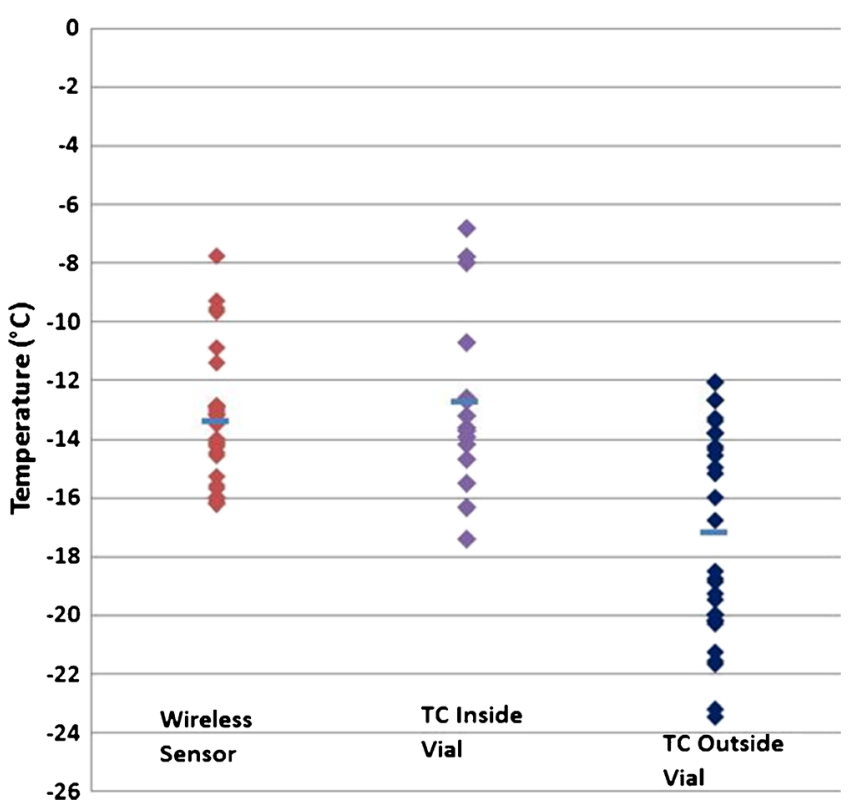

Fig. 2. Comparison of ice nucleation temperatures for vials containing a temperature probe versus vials where the temperature probe is attached to the outside surface of the vial an array of vials is placed on a cooled shelf. As the technology matures for controlled nucleation in freeze drying, using either rapid depressurization (3) or introduction of an ice fog (4) - we can expect that there would be less bias between monitored vials and the rest of the batch.

In addition to the bias introduced by temperaturemeasuring devices, there are other sources of uncertainty in the integrity of product temperature data that are particularly prevalent in a production environment. Figure 3 is a photograph of product thermocouples that are commonly used in a production setting. There are at least two things "wrong with this picture." First, there is no provision for securing the tip of the thermocouple in a fixed position in contact with the product. Second, the heavy gauge of the thermocouple wire and the consequent stiffness and weight of the wire add to the uncertainty as to exactly what temperature is being measured. The heavy gauge thermocouple wire can cause monitored vials to be partially tipped, such that the vial is not setting in an upright position. Visibility within a production freeze dryer is limited, even when sight glasses are provided, so that an operator has no way of visually verifying that a probed vial is as representative of the batch as possible. The heavy gauge of the wire can also cause problems with the wire disrupting vials located between the monitored vials and the thermocouple connector at the front of the freeze dryer. The features of product temperature measurement illustrated in Fig. 1 should be equally valid in a manufacturing setting. It is probably true that finer gauge wires are more easily broken than larger wires, but thermocouple wire is relatively inexpensive, particularly considering the high cost of injectable pharmaceuticals and the high cost of freeze drying equipment. The advantages of fine-gauge thermocouple wires would appear to outweigh the disadvantages.

A significant logistical problem with temperature monitoring in a production environment is the use of automated loading/unloading systems. Such systems give limited, if any, access to vials for insertion of temperature probes. Some manufacturing systems also use sub-doors on the front of the freeze dryer ("pizza" doors), where, after a shelf is loaded, the shelf stack indexes upward, and that shelf is no longer accessible for manually placing probes in vials.

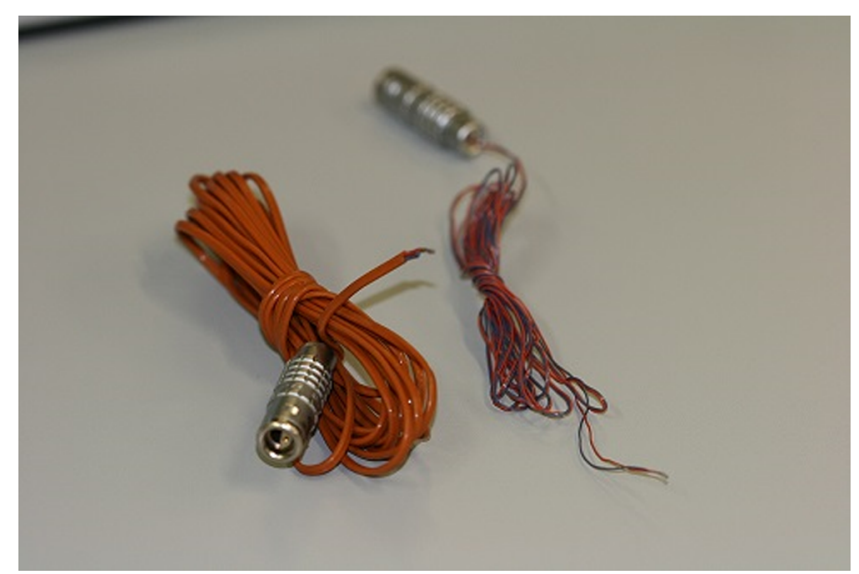

Fig. 3. The thermocouples shown here are representative of thermocouples commonly used in a production environment for product temperature measurement 
Table I. Examples of Thermocouple Composition

\begin{tabular}{|c|c|c|c|}
\hline Type & Materials & $\begin{array}{l}\text { Sensitivity } \\
\text { (average } \\
\mu \mathrm{V} /{ }^{\circ} \mathrm{K} \text { ) }\end{array}$ & Comments \\
\hline S & $\begin{array}{l}\text { Platinum/ } \\
\text { platinum }+10 \% \\
\text { rhodium }\end{array}$ & 10 & $\begin{array}{l}\text { Loses sensitivity at low } \\
\text { temperature }\end{array}$ \\
\hline $\mathrm{T}$ & $\begin{array}{l}\text { Copper/ } \\
\text { constantan }\end{array}$ & 43 & $\begin{array}{l}\text { Seems to be the most } \\
\text { commonly used } \\
\text { thermocouple in freeze } \\
\text { drying }\end{array}$ \\
\hline K & Chromel/alumel & 41 & $\begin{array}{l}\text { The most common general- } \\
\text { purpose thermocouple }\end{array}$ \\
\hline $\mathrm{E}$ & $\begin{array}{l}\text { Chromel/ } \\
\text { constantan }\end{array}$ & 68 & $\begin{array}{l}\text { The highest emf output of } \\
\text { any thermocouple. Good } \\
\text { for low temperatures }\end{array}$ \\
\hline $\mathrm{J}$ & Iron/constantan & 50 & $\begin{array}{l}\text { Wires become brittle at low } \\
\text { temperatures }\end{array}$ \\
\hline
\end{tabular}

Another disadvantage of product temperature probes in a production setting is that insertion of any type of probe into an open container of product is necessarily a manual operation. Regardless of the care taken to maintain asepsis, this type of operation cannot help but compromise sterility assurance to some extent. For this reason, in many production operations, temperature probes are placed only in vials on the front row of the freeze dryer, since this can be done without reaching over the tops of partially open vials of product. While this is good practice from the standpoint of sterility assurance, the front row is a very non-representative location because of the "edge-effect", where vials on the edge of an array of vials, particularly the edge near the door, receive additional heat via thermal radiation (5).

\section{Thermocouples Vs. Resistance Temperature Detectors (RTDs)}

Many people use the term "thermocouple" to describe any temperature-measuring device. In fact, two types of temperature-measuring devices are in common use for product temperature monitoring-thermocouples and resistance temperature detectors or RTDs. A thermocouple consists of two wires made from different metals, joined together at the ends. When the two ends are placed at different temperatures, a voltage difference develops between the two junctions, and a current flows in the circuit. This is known as the Seebeck Effect. While any two metal combinations behave in this way, only a few combinations are important industrially. Some examples are shown in Table I.

The type $\mathrm{T}$ thermocouple seems to be the most commonly used thermocouple in freeze drying. Although the type E, with its high output, particularly at low temperatures, would seem to be ideal for freeze drying applications, it is not commonly used. Neither type S nor type $\mathrm{J}$ would be good choices for freeze drying, either because of low sensitivity at low temperatures (type S) or because the wires become brittle at low temperatures (type $\mathrm{J})$. It has been noted in a personal communication to one of the authors (SLN) that the copper in copper-constantan thermocouples tends to "work harden" and become more brittle with repeated use. While there is no evidence that this "work hardening" causes systematic errors in temperature measurement, it would make type $\mathrm{T}$ thermocouples more prone to breakage, resulting in an open circuit. Regular replacement of thermocouples should be considered and, of course, any thermocouple registering an open circuit should be discarded.

Given that thermocouples generate only tens of microvolts per degree temperature difference between the measurement junction and the reference junction, it is important to avoid introduction of any metal other than the appropriate thermocouple materials anywhere in the circuit, particularly in areas where there are large temperature gradients. Connectors and feedthroughs should be constructed only of thermocouple materials. It is also important to route thermocouple wires such that they are not near wires carrying a large current because the large current can induce a current in the thermocouple circuit, causing systematic errors.

A resistance temperature detector is based on the idea that the resistance of a metal varies in a precise and reproducible way with temperature. A common type of RTD is a 100-ohm platinum wire wound around a core material and covered with some type of sheath (Fig. 4). This wire is placed on one side of a Wheatstone bridge circuit, with the other side incorporating a reference resistor carrying the same current. RTDs are better than thermocouples in terms of accuracy, precision, linearity, and stability. For this reason, temperature measurement at fixed points in a freeze dryer, such as in the heat transfer fluid at the inlet manifold to the shelves, on the condenser, and in the drain lines are usually RTDs. An attribute of thermocouples that makes them particularly useful for product temperature measurement, however, is that the thermocouple measures temperature at the point where the two wires are joined; that is, it is a "point" measurement. An RTD measures the average temperature over the area of the sensing element. As discussed above, it is important to monitor the product at the warmest point, which is at the bottom of the frozen material. As seen in Fig. 4, the temperature measured is the

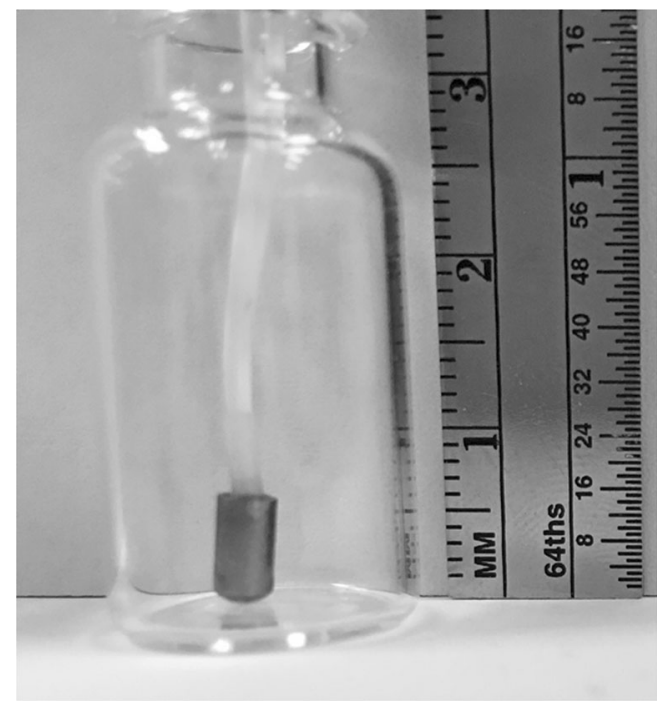

Fig. 4. Vial containing a $100 \mathrm{ohm}$ platinum RTD sensor 


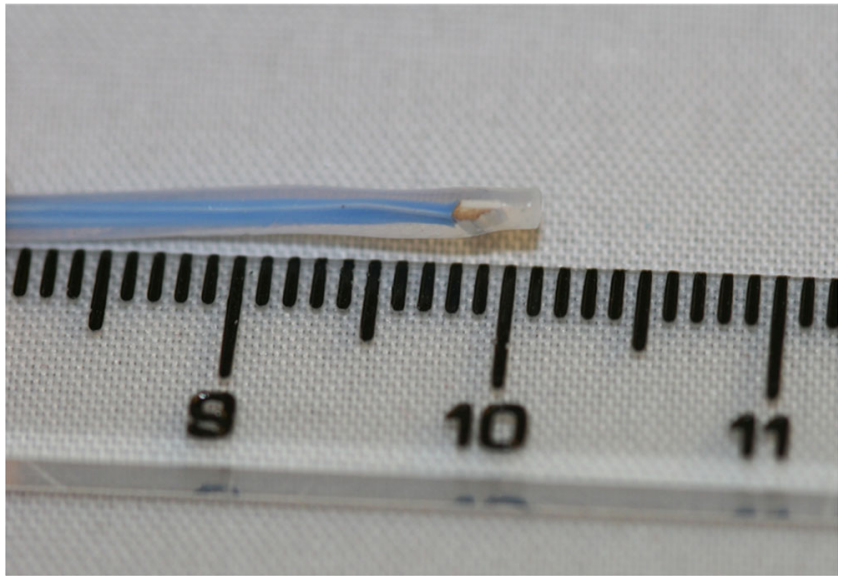

Fig. 5. As RTD sensing elements become smaller, as shown here for a temperature data logger (Ellab), they more closely approximate a "point" temperature measurement

average temperature of the exposed area of the element. For this type of sensor, the measuring element is partially immersed in the frozen matrix and partially embedded in the partially dried solid for most of primary drying, so the average temperature would be misleading.

Some newer RTD systems incorporate much smaller sensing elements than older RTD systems, which tend to be relatively bulky. The larger the sensing element, the larger the discrepancy between the RTD and a thermocouple. An example of more recent RTD-based technology is the data logger (Ellab, Hilleroed, Denmark) shown in Fig. 5. Note the small sensing element. Of course, as the size of the sensor decreases, the more closely the measurement approaches a "point" measurement. Provided that the sensor is located in the bottom of the vial, the smaller sensor minimizes the problem of the sensor being partially embedded in frozen material, and partially embedded in the dried layer. In fact, there is probably an optimum sensor size that combines the advantages of "point" sensing of a thermocouple with the relative insensitivity of the measuring element to small changes in the position of the sensor (see discussion below). With the data logger shown in Fig. 5, there is still a lead wire from the sensing element to the logger, so the same consideration would apply to incorporating a device to secure the sensing element in the middle of the vial, touching the bottom. The logger must also be positioned in such a way that it does not interfere with freeze drying operations, such as stoppering.

\section{A Note on Calibration of Thermocouples and RTDs}

It is typical for freeze dryers to use thermocouples for product temperature monitoring and RTD's for process control. There is no industry standard with respect to calibration frequency or the number of reference temperatures to be used for calibration. RTDs, having a much more linear response than thermocouples, require fewer temperature points for calibration. A typical procedure is to place temperature probes in a stirred liquid reference bath (liquid is preferred over "dry" baths because of better temperature uniformity in liquid baths, as well as better thermal contact with the sensor). Calibration points in the range of -50 to $-20^{\circ} \mathrm{C},-20$ to $0^{\circ} \mathrm{C}$, and 110 to $130^{\circ} \mathrm{C}$ are representative. The temperature indicated on all system devices, such as recorder, controller, and control system displays, should be within $0.5^{\circ} \mathrm{C}$ of each reference temperature. If not, the system needs to be adjusted accordingly. If an adjustment is needed at any reference temperature, then accuracy at each of the other temperatures needs to be re-checked. A typical recommended calibration frequency is every 60 freeze dry cycles or every 6 months, whichever comes first.

\section{Recommended Best Practice for Product Temperature Measurement}

In our opinion, best practice with respect to product temperature measurement can be summarized as follows:

- Despite the fact that RTD's are, in many ways, superior to thermocouples, thermocouples are preferred because of the ability to measure temperature at a precise point. The most appropriate point to measure product temperature is in the center of the vial, with the tip of the thermocouple touching the bottom of the vial.

- Fine-gauge thermocouple wire is preferred because of the flexibility of the wire and the ability to locate the tip of the thermocouple in a precise location. For example, for small fill volumes in small vials, a 36-gauge thermocouple is a good choice. For larger fill volumes in larger vials, a somewhat larger gauge, such as 30 , would be appropriate.

- Use some type of device to hold the thermocouple in place within a monitored vial. The open area of this device should be very close to that of a partially stoppered vial.

- Be aware of the sources of uncertainty associated with product temperature measurement in a manufacturing setting, and do not over-interpret such data.

- Be aware of the bias in freezing and freeze drying behavior caused by any temperaturemeasuring device. Recognize that monitored vials may freeze dry significantly faster than the rest of the batch.

- The same best practices that apply at the laboratory scale should also apply in a manufacturing environment.

\section{CHAMBER PRESSURE MEASUREMENT IN FREEZE DRYING}

There are many types of pressure transducers, and a review of all of them is beyond the scope of this article. We focus on two types-thermal conductivity-type sensors and the capacitance manometer. Both types are commonly used in pharmaceutical freeze drying, but are often not applied in the most useful way.

\section{Thermal Conductivity-Type Gauge}

There are two basic types of thermal conductivity-type pressure gauge - a thermocouple gauge and a Pirani gauge. 
The thermocouple gauge consists of a thermocouple spotwelded to a heated filament. The filament, fed by a constant current, reaches a temperature determined by the rate of energy loss from the filament by a combination of thermal radiation and conduction through the process gas. Energy loss by thermal radiation is kept small by using a filament with a low thermal emissivity, such as platinum. The higher the pressure in the system, the more rapid the rate of energy loss from the filament. The output of this gauge is very non-linear, and the useful pressure range is rather small-only about 2 orders of magnitude. Thermocouple pressure gauges are usually found on the less expensive laboratory-scale freeze dryers.

In the Pirani gauge, two filaments are used as the two "arms" of a Wheatstone bridge. One filament is the reference filament, maintained at constant pressure and gas phase composition. The other filament is the measurement filament. In the Pirani gauge, the filament temperature is controlled at a constant value, and the current needed to do so is monitored. A Pirani gauge has about 100 times the useful range of a thermocouple gauge, and is thus the preferred thermal conductivity-type instrument for freeze drying.

An important characteristic of any thermal conductivitytype gauge is that the response is a function of the composition of the vapor phase being monitored. This is important in freeze drying because the composition of the gas phase in the chamber changes dramatically, from being essentially $100 \%$ water vapor during the primary drying phase to essentially $100 \%$ nitrogen (or whatever gas is being bled into the chamber to control pressure) late in secondary drying. The free molecular conductivity of water vapor is about $60 \%$ higher than the free molecular conductivity of nitrogen (6). This characteristic can be used to our advantage as a process monitoring tool, explained below.

It is important to keep in mind that thermal conductivitytype gauges use a hot filament. This brings up a safety concern when freeze drying formulations containing an organic solvent, such as t-butanol. In order for an explosion to take place, two criteria must be met: (1) there must be a high enough concentration of organic solvent to ignite, and (2) there must be enough oxygen present to support combustion (7). Neither criterion is met during primary drying. It appears that the time period of greatest safety risk is during the initial vacuum pull-down, where there may be a relatively high concentration of organic solvent and enough oxygen to support combustion. Because of this risk, it is considered best practice to turn off thermal conductivity-type gauges when freeze drying products containing an organic solvent. Alternatively, the product chamber could be flushed with nitrogen prior to starting freezing.

It is important to be aware that different Pirani gauges vary in their robustness to repeated steam sterilization. We are aware of no controlled studies to determine the mechanism of failure. Possible modes of failure could be overpressurization (the upper pressure limit for most Pirani gauges is about 1000 Torr) or exposure to excessively high temperature. However, it is likely that the ability to withstand repeated steam sterilization has more to do with the composition of the filament. Several filament compositions are used, including tungsten/rhenium, platinum/iridium, platinum/rhodium, platinum, and gold-plated tungsten. One of the co-authors (PC) has tested a gauge designed for corrosive environments. This gauge uses a platinum/iridium filament, and was demonstrated to withstand 80-100 steam sterilization cycles. This gauge has still not failed, although it is steam sterilized less frequently. In contrast, he tested another gauge, which uses a gold-plated tungsten filament. This gauge failed after two or three sterilization cycles. It is probably wise to assume that a Pirani gauge will fail at some point and require replacement, but it is important to be careful in selection of the gauge.

\section{The Capacitance Manometer}

All capacitance-based gauges work in one of two ways-either by keeping the geometry of the system constant and allowing the dielectric constant to vary, or by a variable geometry with a constant dielectric constant. The later mechanism is the basis for the capacitance manometer pressure gauge. There are two sides of the transducer-a reference side that is evacuated, and sealed, at a very low pressure of around $10^{-7}$ Torr, and a measurement side that is exposed to the process. The sides are isolated by a metal diaphragm, typically Inconel, a high quality stainless steel. As the process pressure changes, the diaphragm flexes, changing the geometry, and therefore the capacitance, of the instrument. Capacitance manometers are the instrument of choice for pharmaceutical freeze drying because of their wide useful range (about four orders of magnitude), accuracy, stability, and linearity. Another compelling feature is that a capacitance manometer measures true pressure-force per unit area-independent of gas phase composition. It is best practice to use a heated transducer in order to avoid the possibility of water vapor condensation inside the gauge, perhaps from steam sterilization, and to avoid the potential for zero drift caused by variation in ambient temperature.

In our opinion, best practice for monitoring the pressure in the chamber and condenser of a freeze dryer is to have both a capacitance manometer and a Pirani gauge on both the chamber and the condenser. This configuration enables what has come to be called comparative pressure measurement. In this process analytical method, the chamber pressure is monitored and controlled using the capacitance manometer. Simultaneously, pressure is monitored using the Pirani gauge. This technique takes advantage of the gas phase composition dependence of the Pirani gauge, where the change in output of the gauge reflects the change in gas phase composition as the process transitions from primary drying to secondary drying. An example of this type of process data is shown in Fig. 6 .

The higher apparent pressure during primary drying as measured by the Pirani gauge reflects the higher thermal conductivity of water vapor, which makes up nearly all of the vapor phase in the chamber during primary drying. As sublimation of ice is completed, the apparent chamber pressure drops. The width of the transition region from pseudo steady state during primary drying to equilibration with the capacitance manometer is a measure of the vial-tovial consistency in primary drying rate-the more uniform the vial-to-vial sublimation rate, the sharper the apparent pressure drop during the transition. For example, the "edge effect," where vials at the edge of an array of vials dry faster 


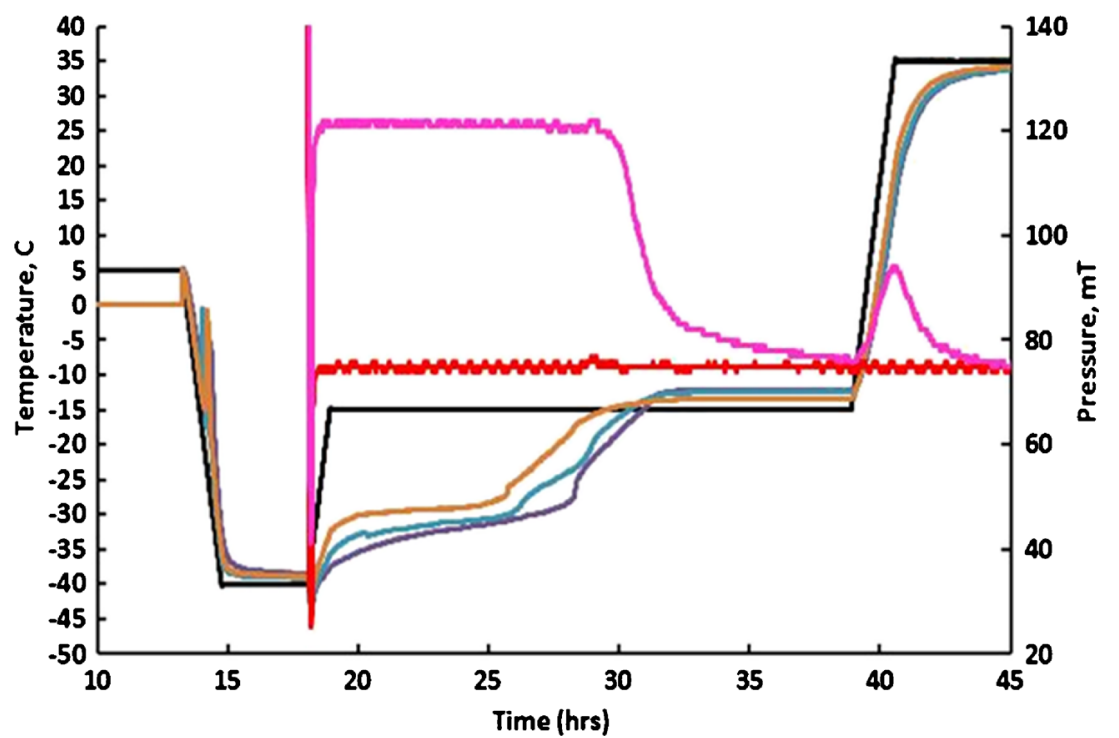

Fig. 6. Comparative pressure measurement as a process monitoring method: Pirani gauge (magenta), capacitance manometer ( red). The shelf temperature is indicated by the black line. The other lines are individual product temperatures, measured by thermocouples

than the vials in the center of an array, would be reflected in a more gradual decrease in apparent pressure at the end of primary drying. It is considered good practice to wait until the Pirani reading has nearly reached the capacitance manometer reading before increasing the shelf temperature for secondary drying. In general, a difference in pressure readings of from 5 to $10 \mathrm{mT}$ seems to work well as long as the steady-state pressure during primary drying is more than about $40 \mathrm{mT}$. Some freeze dryer manufacturers offer the very useful option of sequencing the cycle from primary to secondary drying based on the difference in apparent pressure between the capacitance manometer and the Pirani gauge.

The main advantage of comparative pressure measurement is that it does not depend on monitoring of individual product vials but rather the composition of the vapor phase in the chamber. The technique has proven to be sensitive, reliable, and robust. One note of caution is that if any vials should fall from the shelf to the bottom of the dryer, thus drying at a non-representative rate, these vials can "fool" the Pirani gauge and give an abnormal response.

As shown in Fig. 6, comparative pressure measurement is also useful for monitoring the progress of secondary drying. Typically, there is a "burst" of water vapor from the product early in secondary drying as unfrozen water from the formulation is released at higher product temperatures. As the Pirani reading returns to the capacitance manometer reading, very little additional drying takes place at that shelf temperature. It appears that the only significant process variable during secondary drying is the shelf temperature, as previously reported by Pikal and co-workers (8).

It is best practice to control chamber pressure based on the capacitance manometer, simply because it measures true pressure, independently of vapor phase composition. A capacitance manometer is more accurate, more linear, and more stable than a Pirani gauge. Some operations carry out pressure control based on the Pirani gauge, and detect the end point of primary and secondary drying by a rise in the pressure as measured by the capacitance manometer. This is not a good idea from the standpoint of process consistency, and could cause problems in transferring process conditions from one manufacturing site to another, particularly if no one is paying attention to the details of pressure measurement and control. There is also a risk of exceeding the critical product temperature when carrying out the process close to the critical product temperature near the end of primary drying. As the relative partial pressure of water vapor decreases, nitrogen flow increases to maintain the set point. This results in an increase in absolute pressure, increased heat transfer, increased product temperature, and increased risk to the product.

Why put capacitance manometers on both the chamber and the condenser? This is primarily because the ratio of the chamber pressure to the condenser pressure can serve as a measure of equipment performance. Any freeze dryer has a maximum sublimation rate that it will support at any given pressure, and there is a general lack of quantitative understanding of equipment capability across the industry. There are several factors that can limit equipment capability-refrigeration capacity, condenser surface area, and an upper limit on the attainable shelf temperature. Another limiting factor has to do with "choked flow," first reported as a source of uncertainty in scale-up of freeze drying by Searles (9). Briefly put, choked flow arises from the fact that there is a thermodynamically imposed speed limit on how fast water vapor can travel from the chamber to the condenser-the speed of sound. As the sublimation rate increases and the vapor velocity approaches sonic velocity (about $350 \mathrm{~m} / \mathrm{s}$ for water vapor at room temperature), the vapor flow rate becomes independent of the pressure on the condenser side of the duct connecting the chamber and the condenser. The choke point can be measured by ice slab testing, where tray rings are lined with plastic, and partially filled with water. The water is then frozen, the system is evacuated, and the pressure is controlled at the low end of the pressure range of the freeze dryer. Once the system equilibrates, the shelf temperature is increased until the set 
point pressure can no longer be maintained. The mass flow rate of water vapor at this point is the choke point of the system. A new pressure set point is then established, the shelf temperature is systematically increased again, and a new choke point is reached at the higher pressure. This task is simplified by the fact that the relationship between the choke point and the chamber pressure is linear as long as the condenser temperature does not increase significantly as the water vapor flow rate increases. An alternative approach is called the minimum controllable pressure method, where the pressure set point is at an unattainably low value, such as $10 \mathrm{mT}$. The shelf temperature is increased in stepwise fashion. At each shelf temperature, the pressure will reach a steadystate level that corresponds to choked flow.

The easiest way to measure the mass flow rate at the choke point is by tunable diode laser absorption spectroscopy (10) or TDLAS (see discussion below). Where TDLAS is not available, the mass flow rate corresponding to choked flow can be measured gravimetrically after stopping the process at a point where most of the initial ice load remains. This requires more work because a separate experiment is needed at each pressure setting in order to determine the average mass flow rate. Heat flux measurement (see discussion below) is another method of measuring the sublimation rate and should give data comparable to TDLAS.

An alternative way, at least in principle, to identify the choke point is the pressure ratio between the chamber and the condenser, particularly when a cylindrical duct connects the chamber to the condenser. For a cylindrical duct, the pressure ratio corresponding to the onset of choked flow is $3: 1$ (11). Choked flow would not apply to freeze dryers with an internal condenser design. Some newer freeze dryers have a different chamber/condenser configuration, where the condenser is located beneath the chamber, separated by a rectangular plate that is moved up and down hydraulically (Fig. 7). It would be very useful to be able to identify the choke point by measuring the chamber to condenser pressure ratio for this configuration. A relevant research question is whether the critical pressure ratio could be calculated for this design.

While the authors are not aware of their use in freeze dry process monitoring, perhaps it should be pointed out that

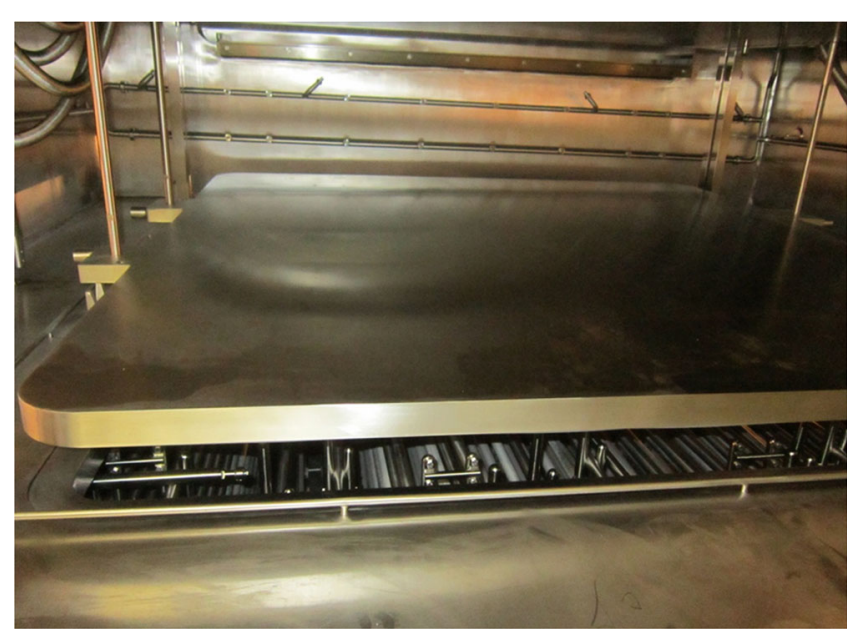

Fig. 7. In this freeze dryer, the condenser is located below the chamber, separated by a hydraulically actuated plate differential capacitance manometers are available. These instruments are used to measure pressure differences between different locations. They are commonly used in monitoring of pressure differentials in adjacent areas in the context of contamination control technology. However, we are aware of no reason why differential capacitance manometers could not be used to monitor the pressure difference between the chamber and the condenser.

Finally, why is it a good idea to have a Pirani gauge on the condenser? First, occasionally there is a leak somewhere in the system that prevents any vacuum from being established. For example, in many laboratory-scale freeze dryers, the gasket on either the chamber door or the condenser door may not seat properly. Having a Pirani gauge on both the chamber and the condenser helps to quickly locate the leak source. Although the Pirani gauge may not be very accurate at pressures just below atmospheric, this does not matter for this type of troubleshooting. The Pirani gauge should begin reading as soon as any vacuum has been established. Capacitance manometers are not useful here because they will not give a reading until the pressure reaches the upper limit of the range of that gauge, usually either 1 or 10 T. Second, having both a Pirani gauge and a capacitance manometer on both the chamber and the condenser could enable use of the connecting duct as a mass flow meter, with the aid of computational fluid dynamics. This is currently an active project in the LyoHub consortium, and it could prove useful for measurement of equipment capability curves, particularly for large freeze dryers not equipped for tunable diode laser absorption spectroscopy.

\section{Pressure Rise Testing}

The pressure rise test (PRT) is a procedure that has been used for decades and involves a quick isolation of the drying chamber from the condenser during the drying process by briefly closing the valve between the chamber and the condenser. When PRT is performed during primary drying, it results in a characteristic pressure rise pattern. Initially, when the valve is closed, the pressure rises rapidly, followed by a slow, almost linear, increase in the pressure. During secondary drying, the chamber pressure increases roughly linearly when the isolation valve is closed. Neumann (12) suggested that this inflection point in the pressure rise curve during primary drying could be considered as an indicator of the saturation pressure over the sublimation surface. He proposed using this pressure inflection point for the estimation of batch average product temperature from the vapor pressure versus temperature of pure ice. Neumann also assumed that the method could enable the measurement of the residual water content. Willemer (13) modified the PRT method to also measure sublimation rates. Many modern commercial freeze-dryers have been equipped with the PRT option. While PRT provides significant opportunities for process monitoring, it is mostly used for the end point determination for both primary and secondary drying steps.

An improvement on the pressure rise test, manometric temperature measurement (MTM), enables calculation of the product temperature during primary drying by fitting the pressure rise data to a set of equations that take into account four mechanisms that contribute to the pressure rise: (i) direct 
sublimation of ice through the dried product layer at a constant temperature, (ii) an increase in the temperature at the sublimation interface due to equilibration of the temperature gradient across the frozen layer, (iii) an increase in the ice temperature due to continued heating of the frozen matrix during the measurement, and (iv) leaks in the chamber, which in practice are normally negligible (14). This analysis yielded reasonable estimates of product temperature, mass transfer resistance of the cake, and vial heat transfer coefficient. A limitation of manometric temperature measurement is that it requires a valve between the chamber and condenser that cycles very rapidly compared with the time course of the pressure rise measurement, which is usually not more than $30 \mathrm{~s}$. The isolation valves of most production-scale freeze dryers cycle too slowly to allow meaningful MTM measurements. However, the investigation of MTM has shown that the increase in chamber pressure during PRT/MTM is a function of load, chamber dimensions, product temperature, and progression of the primary drying step. For example, pressure increase is larger and faster with increase in a batch size, decrease in the size of the chamber and with increase in product temperature during primary drying. It is, therefore, advisable to take in account all these factors in order to establish meaningful PRT parameters during both primary and secondary drying steps.

\section{Calibration of Pressure Sensors}

For calibration of capacitance manometers, a transfer standard is used, which is another capacitance manometer. Thermal or mechanical gauges should never be used to calibrate a capacitance manometer because capacitance manometers are much more accurate. Capacitance manometers used in pharmaceutical freeze drying generally have an accuracy specification of about $0.25 \%$ of reading, as compared with $5-25 \%$ for a Pirani or thermocouple gauge in the same range (15). Capacitance manometers used as transfer standards typically have an accuracy of $0.05 \%$ of reading. There are three basic approaches to calibration-in situ, onsite, and off-site. With in situ calibration, the unit under test is not removed from the freeze dryer. Instead, the transfer standard is connected to the vacuum chamber using a port as close to the unit under test (UUT) as possible, perhaps by using a $\mathrm{T}$ connection where the transfer standard can be connected close to the UUT. Best practice for calibration, however, is to pump the vacuum system to below the resolution of the capacitance manometer in order to set the zero. Unfortunately, a freeze dryer cannot be evacuated to a pressure level below the resolution of the instrument. With on-site calibration, the UUT is removed from the freeze dryer and connected to a calibration system consisting of a highvacuum pumping system, a transfer standard, and a pressure control system. With off-site calibration, the sensor is removed from the freeze dryer and sent to a calibration facility. The following guidelines apply to capacitance manometer calibration:

- Both the unit under test and the transfer standard must be operated for at least $4 \mathrm{~h}$ after power has been applied, and must be at normal operating temperature.
- $\quad$ The instrument must be zeroed by pumping the system to below the resolution of the UUT. A recommended zeroing pressure is four decades below full scale.

- Six data points are generally considered adequate to ensure that the instrument is within calibration limits. Recommended calibration points are 10 , $20,40,60,80$, and $100 \%$ of full scale reading.

Regarding frequency of calibration, it is good practice to collect historical data (see discussion of data historians below). Conditions of use are important in establishing the appropriate calibration interval. Most capacitance manometers on freeze dryers are routinely exposed to atmospheric pressure, as opposed to being isolated at low pressure. This would dictate more frequent calibration. Also, repeated steam sterilization would tend to require more frequent calibration. According to Osborn and Hansen (15), capacitance manometers on steam sterilized units should be calibrated every 3 months. Capacitance manometers that are isolated from atmospheric pressure can have much longer periods between calibrations.

Pirani gauges are generally calibrated using nitrogen, which explains why the apparent pressure during primary drying is well above the pressure indicated by the capacitance manometer. The approach to calibration is generally the same as discussed above, where the transfer standard is commonly a capacitance manometer. Calibration of Pirani gauges is less critical than calibration of the capacitance manometer, assuming that the capacitance manometer is used for pressure control. The reason is that, with the Pirani gauge, we are much more interested in changes in apparent pressure than in accurate absolute pressure measurement.

\section{Summary of Best Practice for Pressure Measurement}

- The capacitance manometer is the instrument of choice for pressure measurement and control in a pharmaceutical freeze dryer. A temperaturecontrolled sensing head is highly recommended.

- Best practice would include both a capacitance manometer and a Pirani gauge on both the chamber and the condenser.

- Use of comparative pressure measurement is highly recommended as a process monitoring tool to determine the end point of both primary and secondary drying.

- Keep in mind that both repeated exposure to atmospheric pressure and repeated steam sterilization tend to shorten the interval between calibrations of a capacitance manometer. Historical records are useful in establishing the more appropriate time interval between calibrations. In situ calibration is not considered best practice.

\section{Other Process Measurements and Data Historians}

In commercial manufacturing, it is important not only to monitor a wide range of process and equipment 
parameters but also have the ability to quickly retrieve these data from past manufacturing runs to observe trends. Such trending is useful as a tool to track equipment performance for maintenance and reliability purposes. It is also a key aspect of continuous process verification for pharmaceutical manufacturing (ICH Q8(R2)). There are a number of parameters that should be monitored and recorded in addition to the obligatory shelf fluid inlet temperature (often called shelf temperature): chamber pressure, product temperatures, and Pirani pressure gauge. Table II presents some examples of useful monitoring points. In general, data should be recorded at least every minute in order to detect transient events. Note that parameters necessary for monitoring and verifying cleaning and sterilization are not included here.

\section{A BRIEF SURVEY OF DEVELOPING TECHNOLOGY FOR PROCESS MONITORING}

As mentioned above, this paper is a "snapshot" of current best practice. There are other process analytical tools that merit consideration for measurement of the status of the product that may become "best practice" in the future. These include wireless temperature measurement, tunable diode laser absorption spectroscopy, heat flux measurement, and mass spectrometry.

\section{Wireless Product Temperature Monitoring Systems}

Wireless temperature sensing systems appropriate for freeze drying have appeared in the past few years. In the data logger system discussed briefly above, the temperature data are stored within the device and retrieved using a reader station, although there is a version of this technology where the data can be transmitted in real time, using the logger system as a back-up. One reported disadvantage of this system is the reliance on batteries, and repeated steam sterilization has been reported (unpublished data) to adversely affect battery life, particularly when the process data are transmitted in real time.

Another recent wireless system is the temperature remote interrogation system (Tempris ${ }^{\circledR}$, iQ Mobil Solutions, GmbH, Holtzkirchen, Germany). A vial containing the sensing element is shown in Fig. 8a. This sensor is neither a thermocouple nor a RTD. The sensing element consists of a quartz crystal that vibrates at a frequency that is a function of its temperature. The system consists of an interrogation unit, including a transmitter and associated software. The sensors receive their power by excitation of the passive transponder by means of a modulated electromagnetic signal in the internationally usable $2.4-\mathrm{GHz}$ ISM band, with evaluation of the back-scatter response. The signal is demodulated in the transponder by means of a diode detector and used to stimulate the quartz-based resonance circuit. In the second step, the amplitude modulation is deactivated and only the continuous wave (CW) carrier is radiated. The stimulated resonance circuit continues to oscillate at its characteristic frequency which depends on its temperature. This free oscillation frequency is mixed with the $\mathrm{CW}$ carrier and re-transmitted to the interrogation unit. This unit measures the frequency of the response modulation and the exponential drop in amplitude. In combination with statistical parameters of several consecutive responses, the temperature is calculated. Each interrogation unit can accommodate up to 16 individual sensors.

This is relatively new technology, and there has been little published experience with this system in pharmaceutical freeze drying, so recommendations of best practices concerning this system are probably premature. Schneid and Gieseler (16) evaluated this system for application in freeze drying with respect to measurement accuracy, capability of accurate end point detection for primary drying, and the effect of sensor positioning. Thermocouples were used for comparison as well as manometric temperature measurement. These investigators reported excellent agreement between the wireless system and thermocouples, where thermocouples were placed in the bottom center of vials. They further reported that the wireless system gave more reliable temperature profiles as well as a more reliable indication of the end point of primary drying in cases where temperature sensors were placed in vials at the edge of a vial array.

The appeal of a wireless system is obvious, particularly in a manufacturing setting, since the troublesome lead wires are avoided. This system can be used, at least in principle, with automatic loading systems by, for example, using sterile forceps to place the probed vials on the filling line just before vials reach the loader/unloader accumulator table. The same instrument can be used at both the laboratory and production scale, since there is essentially no permanent installation. Figure 9 is a photograph of the interrogation unit mounted at the sight glass of a production-scale IMA Life freeze dryer. At laboratory scale, this unit would probably be placed on the Plexiglas $₫$ door. There must be an optical path between the transmitting unit and the temperature sensor so, at production scale, there must at least be a sight glass available. Experience at Baxter Bloomington, as well as at Pfizer, has been that placement of the transmitter as shown in Fig. 9 seems to reach probed vials placed anywhere in the chamber.

A potential disadvantage of this type of sensing element is its bulk. The volume of the sensor can increase the height of the liquid in the vial, and thus extend the primary drying time somewhat. The part of the assembly that must be immersed in the product solution is the bottom-most part of the sensor, as shown in Fig. 8b. It is also important to keep in mind that, if the level of solution reaches the antennae, the signal is lost. Of course, this antenna will be bent during stoppering of vials. It appears, though, that the antenna can be straightened and used again. At worst, the antenna is inexpensive to replace.

Comparative product temperature data are shown in Fig. 10, focusing on the transition from primary to secondary drying. Note that there is considerable variability in the time/ temperature plot for thermocouples, simply because, as discussed above, the thermocouple measurement is a "point" measurement. As the sublimation front advances, the tip of the thermocouple transitions from being immersed in frozen material to being embedded in partially dried material after passage of the sublimation front. These data suggest that perhaps an "area" measurement is best, as long as it is the 
Table II. Process Measurements Useful for Inclusion in Data Historian

Product chamber

Chamber pressure

Chamber interior surface temperatures

Chamber jackets

Gas bleed

Shelf heat transfer fluid

Shelf fluid inlet temperature

Shelf fluid outlet temperature

Individual shelf fluid inlet and outlet T's

Flow rate of shelf heat transfer fluid

\footnotetext{
$\%$ Heating for shelf heat transfer fluid

$\%$ Cooling the shelf heat transfer fluid Condenser

Condenser pressure
}

Condenser coils/plates

$\%$ Cooling for condenser

Vacuum and refrigeration systems

Vacuum foreline pressures

Vacuum systems power
Primary (usually CM) and comparative (usually Pirani)

Should be monitored in order to ensure that the re-cooling following steam sterilization is operating as intended, as well as to better understand the magnitude of thermal radiation heat transfer from the dryer walls to edge vials. Of added value is the temperature of the shelf support structure above the top-most shelf. This structure is often the highest temperature surface in the dryer interior, heat from which affects the upper shelves during drying, and thermal radiation from which is reflected throughout the dryer during the entire cycle

Inlet and outlet temperatures should be monitored in order to ensure that the re-cooling following steam sterilization is operating as intended

Monitor the \% open of the modulating valve for pressure control and/or the actual gas flow rate

Often referred to as just "shelf temperature" the shelf fluid inlet temperature is measured just upstream of the manifold that distributes the fluid among all of the product shelves

The outlet temperature is useful to measure because the difference between the inlet and outlet temperatures is proportional to the thermal load on the shelves

The above shelf fluid outlet temperature is measured downstream of the manifold that returns fluid from all of the shelves. Added utility can be gained by monitoring the outlet temperature of the fluid leaving each shelf, particularly when diagnosing fluid flow problems for individual shelves

The flow rate of shelf heat transfer fluid is important for ensuring highly efficient heat transfer from the heat transfer fluid to the inner surfaces of the shelves. This parameter is usually monitored with a flow switch, but knowledge of the actual flow rate is of added value

Indicative of sublimation load upon the shelf fluid loop, evidence of drying rate and progress of the cycle

Indicative of completion of the freezing step
Absolute pressure in the condenser chamber. Useful for diagnosing choked flow $v s$ insufficient condensation capability for inability to hold chamber pressure
Monitor surface temperatures of each flow path for coils or plates upon which ice condenses in the condenser chamber
Indicative of load upon the condenser, evidence of drying rate and progress of the cycle

Help diagnose vacuum system problems

Manufacturing lyophilizers usually have two redundant vacuum systems in parallel. It is useful to know one(s) are operating at any given time appropriate type of area measurement. With the traditional RTD, shown in Fig. 4, the area of the sensor extends vertically, such that the sensor is embedded in partially dried material throughout much of primary drying. The type of area sensing shown in Fig. 8b, however, is limited to the bottom $2 \mathrm{~mm}$ or so of the frozen matrix. It could be that the time/temperature relationship shown in Fig. 10 is more constant from vial to vial because the sensing element, being larger, stays in better contact with frozen material as the end of primary drying is approached. Thus, a potential advantage of the wireless sensor over thermocouples is that the wireless sensing element is small enough to be located on the bottom of the vial, yet large enough to perhaps give a more meaningful measure of product temperature as the last ice sublimes. More study is warranted.

\section{Tunable Diode Laser Absorption Spectroscopy}

Tunable diode laser absorption spectroscopy, or TDLAS, is a near-IR-based optical method for determining the mass flow rate of water vapor between the freeze dryer chamber and an external condenser by placing optical hardware in the cylindrical duct between the chamber and condenser. A photograph of the connecting duct on laboratory-scale freeze dryer with the TDLAS optical hardware is shown in Fig. 11a. TDLAS is applicable to both laboratory-scale and production-scale equipment, provided that the production freeze dryer is constructed such that the duct (or "spoolpiece") allows for installation of the optical hardware. This is illustrated in Fig. 11b for a production freeze dryer. The discs shown in the photograph 

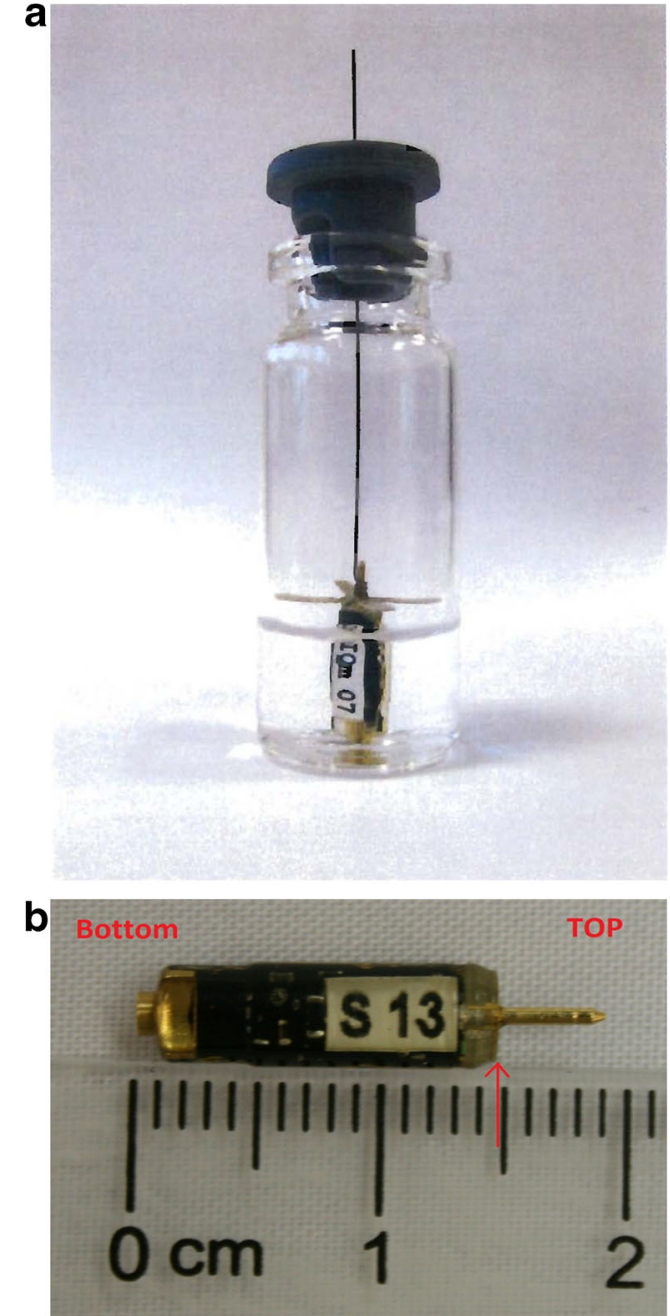

Fig. 8. a Sensing element for wireless temperature measurement system placed in a vial, and $\mathbf{b}$ close-up of the sensing element, showing the sensing region

are removed, and the fiber optic collimator is installed on the "upstream" side of the duct, and the detector is installed on the opposite side of the duct, at a $45^{\circ}$ angle "downstream."

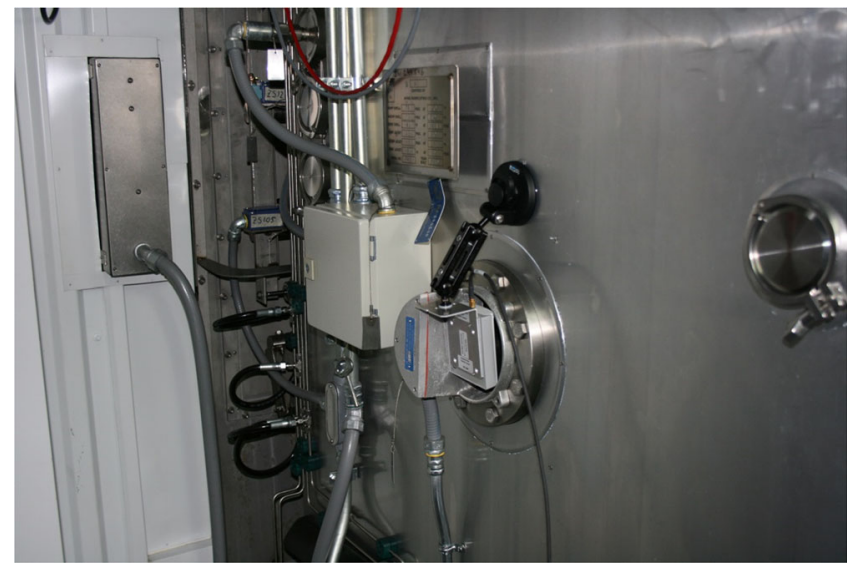

Fig. 9. Transmitter unit of a wireless system mounted at a site glass on a production-scale IMA Life freeze dryer by means of a suction cup
TDLAS has proven to be very useful for cycle development and optimization. The ability to measure mass flow rate enables measurement of batch average vial heat transfer coefficient $\left(K_{\mathrm{v}}\right)$, batch average resistance of the dry product layer to flow of water vapor, and measurement of sublimation rate at the "choke point." This has allowed construction of a graphical design space for primary drying (17).

There may be a perception in the industry that operation, maintenance, and calibration of TDLAS requires highly specialized training. This is largely a misperception. The sensor control unit is designed to operate continuously, and neither the sensor unit nor the optical interface hardware contains any moving parts. Sensor calibration (based on the laser wavelength tuning rate per data point) is performed prior to shipment of the instrument, and it has been demonstrated that the calibration is maintained for the life of the sensor laser. The manufacturer (Physical Sciences, Inc., Andover, MA) recommends periodic validation of the calibration by comparing the sensor integration of total water removed with a gravimetric determination of total water removed. The sensor is specified to agree within $7 \%$ versus gravimetric determination.

We consider TDLAS at production scale to be a stilldeveloping technology. Quantitative accuracy of TDLAS (versus gravimetric measurement) at laboratory scale is generally within about $6 \%$ whereas, on production equipment, discrepancies in mass flow rate of up to $25 \%$ percent have been observed under very aggressive sublimation conditions, such as carrying out choke-point testing using ice slabs. The primary source of this measurement error is likely the measurement of the gas velocity used in calculating the water vapor mass flow rate. The sensor data analysis algorithm predicts the development of the gas flow profile as a function of operation conditions (gas flow velocity, pressure and gas composition) and assumes an axisymmetric velocity profile. The presence of any physical structures in the flow such as clean-in-place/sterilize-in-place (CIP/SIP) piping and nozzles will perturb the axi-symmetric flow and result in measurement errors. Thus, care must be taken when designing freeze dryers when there is an intent to apply TDLAS measurement technology to monitor water vapor mass flow. Another challenge associated with routine steam sterilization of production equipment is the extreme range of temperatures associated with steam sterilization causing some "drift" in the optical alignment across the connecting duct, requiring adjustment of the optical hardware. The glass windows used at the point where the laser is introduced into the connecting duct have been known to crack and require replacement. Again, this is not an issue that has ever been encountered in the laboratory application of this technology.

Another issue that makes application of TDLAS on a production scale problematic is that the demand for the technology across the pharmaceutical industry is not yet strong enough for freeze dryer manufacturers to invest in developing the technology. What is needed is a more robust design of the hardware, where a "spoolpiece" is available with the optical hardware already installed, with a provision for fine adjustments in optical alignment. The software for TDLAS ultimately needs to be integrated into the overall system software. This is not currently available for 


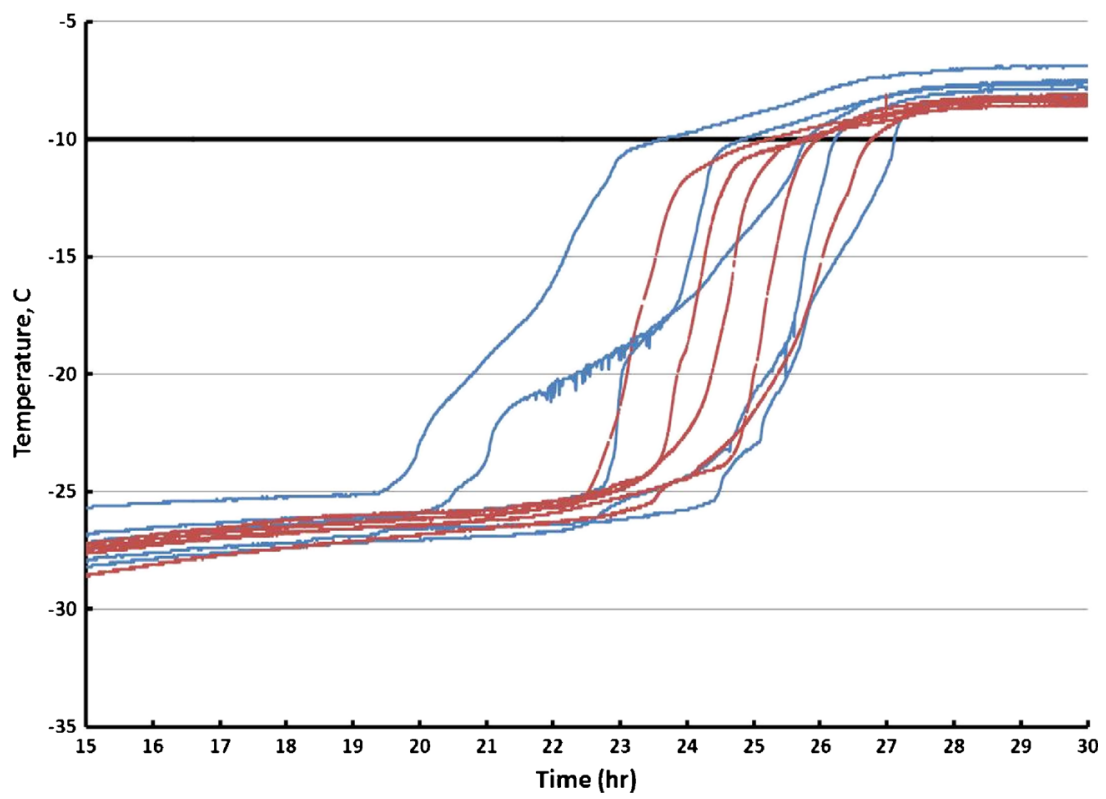

Fig. 10. Comparative product temperature data for wireless sensors (red) and thermocouples (blue). The black line represents the shelf temperature

production-scale dryers. Instead, TDLAS data must be collected on a "stand-alone" basis.

That being said, availability of accurate, reliable TDLAS data on a production scale offers real benefits. Availability of accurate mass flow rate data would allow calculation of accurate batch average product temperature during primary drying. This would provide very useful process analytical data that would provide a benchmark for scale-up and for transfer of cycle conditions from one manufacturing site to another. Batch average product temperature data would also be useful in decision making regarding process deviations. Shelf temperature excursions and chamber pressure excursions are not uncommon in the industry, and investigation of such deviations requires risk analysis and a decision as to the disposition of the batch affected. The most relevant question is whether a given deviation had a significant impact on product temperature, assuming that the deviation occurred during primary drying. Availability of batch average product temperature determinations based on the combination of TDLAS-based mass flow rate determinations and the steady-state model of vial freeze drying would help considerably in answering that question. The cost savings of being able to scientifically justify the conclusion that product quality has not been compromised by a process deviation for even the occasional batch of product, given the frequently very high cost of goods, would justify the investment required to make TDLAS technology more robust in a manufacturing environment.

\section{Mass Spectrometry as a Process Monitoring Tool}

Mass spectrometers as process analytical tools are typically small quadrupole units with an upper limit of mass to charge ratio of perhaps 200 (see Fig. 12). While not widely applied in pharmaceutical freeze drying, mass spectrometry has several potential applications (18). Ability to monitor the partial pressure of water vapor, as well as nitrogen, in the chamber allows process monitoring analogous to comparative pressure measurement, as discussed above. This type of process monitoring has the potential to be used for ending the cycle at a precise residual moisture level if the relationship between partial pressure of water vapor in the chamber and residual moisture level in the product can be established.

Use of a mass spectrometer in conjunction with a helium source can be used for troubleshooting of leaks in the system. For formulations containing an organic solvent, the time course of release of the solvent from the frozen system can be monitored independently of water vapor. Again, there is the potential for being able to end the process at a known level of residual organic solvent in the freeze dried solids.

A typical freeze dryer cycles through large local thermal stresses with operating temperatures ranging from -50 to $121^{\circ} \mathrm{C}$ and pressures ranging from $10 \mathrm{~Pa}$ to $0.2 \mathrm{MPa}$. Based on the ASME section VIII, localized fatigue damage ratio can be as high as $20 \%$ with up to 5000 operating cycles. Moreover, the shelves of a freeze dryer move during clean-in-place/ sterilize-in-place cycles, loading/unloading, and stoppering of vials. In addition, service life of these machines can sometimes exceed three decades. The severity of the thermal and mechanical stresses can sometimes lead to micro cracks that eventually leak silicone oil used as heat transfer fluids in shelves. Initially, these cracks are too small to be observed visually. Mass spectrometry allows such leaks to be detected before the leak can be detected visually.

\section{Heat Flux Sensors}

A heat flux sensor is a thin-film differential thermopile that generates an electrical signal proportional to the total heat applied to the surface of the sensor. The signal is proportional to the difference in temperature and the number of junctions in the thermopiles and is proportional to the heat flow per unit area. Heat flux sensors are simple devices that can be used to measure heat flux in discrete locations. The sensors are unique because they are very thin and offer 


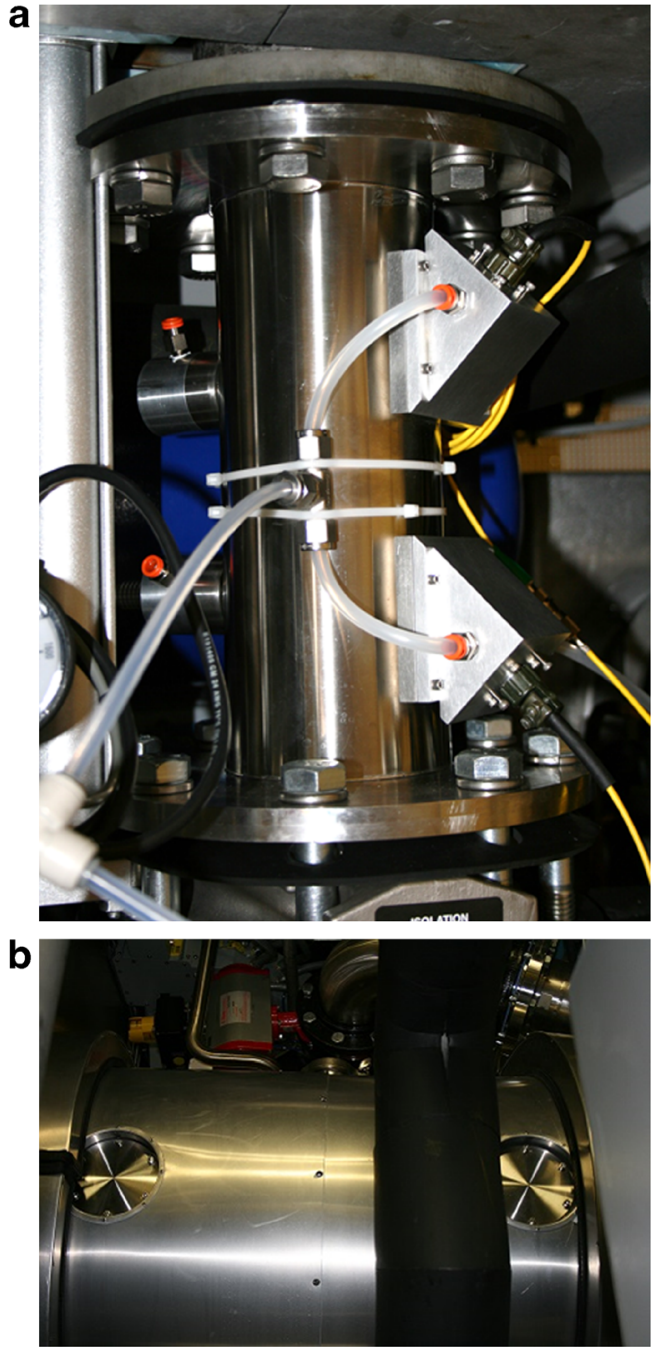

Fig. 11. a Connecting duct between chamber and condenser of a laboratory-scale freeze dryer with TDLAS optical hardware installed. b Connecting duct between chamber and condenser of a productionscale freeze dryer, with blanked-off ports for installation of TDLAS optical hardware

minimal perturbations to the flow of heat. They require no special wiring, reference junctions, or special signal conditioning. The accuracy of the measurement with these devices is optimized by proper installation and the ability to adequately couple the sensor to the materials surrounding it as well as to any prevailing thermal conditions such as convection currents. Being thin and flexible, the sensors can be attached to either flat or curved surfaces and permanently bonded in place with conventional adhesives or epoxies. The heat flux sensor is most commonly placed on the shelf surface to measure heat flow between the shelf and an array of vials. Since multiple sensors can be placed on one shelf, localized heat flow can be readily measured.

Heat flow data can be used to construct a graphical design space by measuring vial heat transfer coefficients and resistance of the dry product layer. Equipment capability can be measured at both laboratory and production scale simply by converting heat flow rate to mass flow rate of water vapor. Thermal events during freezing can be measured as well. This ability is potentially useful for establishing the appropriate shelf temperature and holding

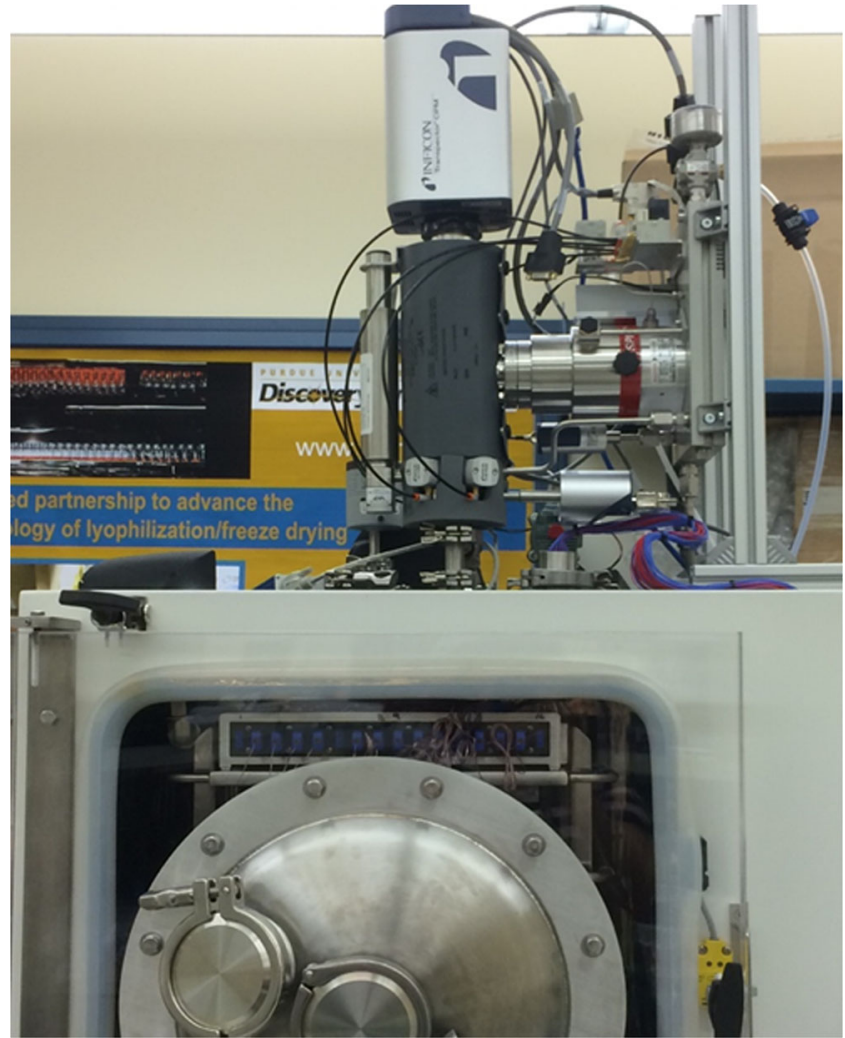

Fig. 12. Quadrupole mass spectrometer installed on a laboratoryscale freeze dryer for in situ monitoring of gas composition in the product chamber

time for crystallization of a formulation component during annealing steps in the freezing process. Another useful feature of a heat flux sensor is the ability to measure the product temperature during primary drying without the use of a thermocouple as long as the vial thermal conductivity is known.

Heat flux sensors can be added to any freeze dryer. Since they provide continuous process measurement, they can be used as a process analytical technology and incorporated into the control system for cycle optimization and control.

\section{AREAS WHERE MORE INFORMATION IS NEEDED}

Several questions for which there appear no readily available answers arose in the course of the preparation of this manuscript. For example, comparative pressure measurement has proven to be a sensitive, reliable, and inexpensive process monitoring tool that allows us to follow the time course of both primary and secondary drying without the need to place temperature probes in individual vials of product, yet it is not as widely employed as it should be. This is partly an education issue, but a contributing issue may be the partially justified point of view that Pirani gauges will not withstand steam sterilization. It would be useful to know more about the mechanism of failure of Pirani gauges, as well as which gauges should be recommended for pharmaceutical freeze drying.

While "point" sensing with thermocouples is preferred for product temperature measurement over traditional RTD probes that measure temperature over a relatively large area, "point" sensing has the drawback of being sensitive to small changes in the location of the tip of the thermocouple. It 
seems that there is an optimum sensor size that measures product temperature very near the bottom of the vial, but is relatively insensitive to small variation in the exact location of the sensing element. The wireless system discussed above appears promising in this regard, but there is not yet enough experience with this technology to merit inclusion of this type of sensor as "best practice." Further experience and more published data will be useful to the industry.

The use of the ratio of chamber pressure to condenser pressure is potentially a useful indicator of when a freeze dryer is approaching the limit of its capability. For a cylindrical duct between the chamber and the condenser, this ratio is 3.0, at least in principle, but this does not take into account the presence of a valve either within the duct or very near the end of the duct. There are other geometries where the critical pressure ratio is not yet known. It is hoped that computational fluid dynamics will be useful in achieving a better understanding of this aspect of equipment performance.

While TDLAS at laboratory scale is a well-established and very useful process analytical tool, more work is needed to achieve reliable and accurate mass flow rate data on production-scale equipment. A part of what is needed is the development of freeze dryer designs that do not result in flow perturbations within the developing gas profile within the duct connecting the freeze dryer chamber and condenser. Computational fluid dynamics modeling could be used to confirm the lack of unwanted flow effects and any subtle aspects of the flow vapor dynamics through the duct.

Another question that may be worthy of an eventual "best practice" paper is development of a scientific rationale for acceptance criteria for silicone levels detected in the chamber.

\section{ACKNOWLEDGEMENTS}

This paper represents a collaborative effort among members of the Advanced Lyophilization Technology Consortium-LyoHUB. Support from NIST Grant No. 70NANB15H067 is gratefully acknowledged.

Open Access This article is distributed under the terms of the Creative Commons Attribution 4.0 International License (http://creativecommons.org/licenses/by/4.0/), which permits unrestricted use, distribution, and reproduction in any medium, provided you give appropriate credit to the original author(s) and the source, provide a link to the Creative Commons license, and indicate if changes were made.

\section{REFERENCES}

1. Hardwick LM, Nail SL, Jarman JG, Hasler K, Hense T. A proposed rationale and test methodology for establishment of acceptance criteria for vacuum integrity testing of pharmaceutical freeze dryers. Eur J Pharm Biopharm. 2013;85:236-9.

2. Li X, Nail SL. Magnetic resonance imaging of freeze drying. J Pharm Sci. 2006;95:2016-25.

3. Konstantinidis AK, Kuu W, Otten L, Nail SL, Sever RR. Controlled nucleation in freeze drying: effects on pore size in the dried product layer, mass transfer resistance, and primary drying rate. J Pharm Sci. 2013;100:3453-70.

4. Brower J, Lee R, Wexler E, Finley S, Caldwell M, Studer P. New developments in controlled nucleation: commercializing VERISEQ ${ }^{\circledR}$ nucleation technology. In: Lyophilized biologics and vaccines. New York: Springer; 2015. p. 73-90.

5. Rambhatla S, Pikal MJ. Heat and mass transfer scale-up issues during freeze-drying I: atypical radiation and the edge vial effect. AAPS PharmSciTech. 2003;4(2):117-26.

6. Dushman S, Lafferty JM, editors. Scientific foundations of vacuum technique. New York: Wiley; 1962. p. 48.

7. Gunderud D. Guidelines for operation of freeze dryers when using non-aqueous solvents, CPPR Conference on Freeze Drying of Pharmaceuticals and Biologicalsk GarmishPartenkirchen, Germany. 2010.

8. Pikal MJ, Shah S, Roy ML, Putman R. The secondary drying stage of freeze drying: drying kinetics as a function of temperature and chamber pressure. Int J Pharm. 1990;60:203-17.

9. Searles JA. Observation and implications of sonic vapor velocity in freeze drying. Am Pharm Rev. 2004;7:58-69.

10. Gieseler H, Kessler WJ, Finson M, Davis SJ, Mulhall PA, Bons $\mathrm{V}$, et al. Evaluation of tunable diode laser absorption spectroscopy for in-process water vapor mass flux measurements during freeze drying. J Pharm Sci. 2007;96:1776-93.

11. Patel SM, Chaudhuri S, Pikal MJ. Choked flow and importance of Mach I in freeze drying process design. Chem Eng Sci. 2010;65:5716-27.

12. Neumann KH. Freeze-drying apparatus, US Patent. 1961. 2994132

13. Willemer H. Measurement of temperatures, ice evaporation rates and residual moisture contents in freeze-drying. Dev Biol Stand. 1992;74:123-36.

14. Milton N, Pikal MJ, Roy ML, Nail SL. Evaluation of manometric temperature measurement as a method of monitoring product temperature during lyophilization. PDA J Pharm Sci Tech. 1997;51:7-16.

15. Osborn G, Hansen S. Calibration of lyophilization pressure gauges. Pharmaceutical Technology, June 2002.

16. Schneid S, Gieseler H. Evaluation of a new wireless temperature remote interrogation system (Tempris $\left.{ }^{\circledR}\right)$ to measure product temperature during freeze drying. AAPS Pharm Sci Tech. 2008;9:729-39.

17. Searles JA, Nail SL. Elements of quality by design in development and scale-up of freeze dried parenterals. Biopharm Int. 2008;21:44-52.

18. Connelly JP, Welch JV. Monitor lyophilization with mass spectrometer gas analysis. PDA J Pharm Sci Tech. 1993;47:70-5. 